
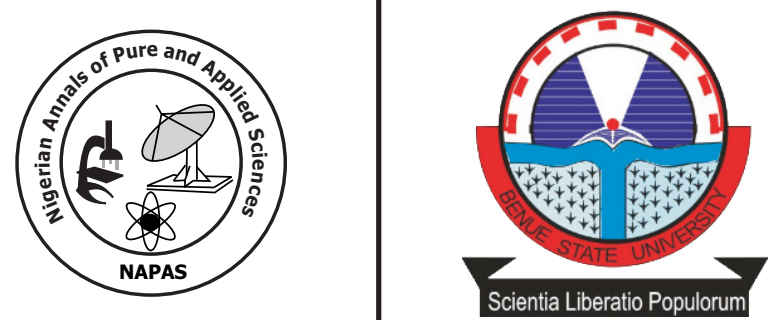

\title{
Prevalence of Gastro- intestinal Parasites of Sheep slaugtered at Keffi Abattoir, Nasarawa Sate, Nigeria.
}

\author{
Abdullahi M. $\mathbf{M}^{1^{*}}$, Okaku, M. S ${ }^{2}$, Tongjura J. D ${ }^{3}$ and Sani Z. R \\ 1. Department of Zoology, Faculty of Natural and Applied Sciences, \\ Nasarawa State, Keffi, Nigeria. \\ 4. Department of Biological Sciences, Federal University Gusau, Nigeria \\ * Corresponding author e-mail:mairiga.nsuk.edu.ng@gmail.com
}

\begin{abstract}
This study investigated the prevalence of gastrointestinal parasites of sheep slaughtered in Keffi main abattoir conducted from June to July 2019. One hundred and fifty (150) fecal samples comprising of 60 Yankasa, 18 West African dwarf(WAD), 33 Balami and 39 Uda breed were collected from the abattoir. The samples were taken to the Laboratory to examine the intestinal helminthes eggs and protozoan oocysts using sodium chloride floatation and sedimentation techniques. Out of 150 samples examined, 84(56.0\%) had gastrointestinal parasites. The Yankasa breed had the highest prevalence of 32(38.1\%), while the WAD breed had the lowest prevalence of 12(14.3\%). Female had the highest prevalence of 54(64.3) than male which have $30(35.7 \%)$. Young sheep had the highest prevalence of 52(61.9\%) than adults which had prevalence of $32(38.1 \%)$ respectively. The gastrointestinal parasites encountered were Strongyles edentates sp., Coccidian spp., Haemonchus spp., Trichostrongyles spp and Fasciola spp. Trichostrongyles spp., had the highest prevalence of $23(27.3 \%)$ while coccidian had the lowest prevalence of $4(4.7 \%)$. Chi-square statistical analysis revealed no significant difference ( $p>0.05$ ) among the breed, age, and sex of the sheep. The result of the study shows that high prevalence of gastrointestinal parasites among the sheep breed, therefore with good management practice, prompt diagnosis, treatment with antihelminthes drugs and mass education of farmers on the importance of hygiene and sanitation will reduce the risk of the disease and increase productivity.
\end{abstract}

Key word: gastrointestinal parasites, abattoir, Strongyles edentates sp, intestinal helminth 


\section{Introduction}

Sheep are important live stocks in developing countries because they provide source of protein and other products like fibers and skins (Hassan et al., 2013a). Nigeria has basically four definitive breeds of sheep which include the West African Dwarf (WAD), the Uda(UD), Balami(BAL) and the Yankasa (YANK) (Olufunmilayo et al., 2000). The WAD sheep is a small breed but not dwarf in the genetic sense. True dwarf are physically weak and poor, whereas the sheep of West Africa have notable physical and sexual vigor and robustness that enables them to withstand the stress of the climate, diseases and irregular feeding (Charray and Levif, 1992).

Gastrointestinal parasites are considered the major diseases causing organisms of small ruminant (sheep) in Nigeria and are of the major importance in many agro-ecological zones as well as a primary factor in the reduction of production and productivity of livestock (Hassan et al., 2013b). The effects of gastro intestinal nematode pose a serious limitation to small ruminants due to associated morbidity, mortality and cost of treatment and control measures (Nwosu et al. 2007). The major factor that influences gastrointestinal parasites infestation in small ruminants, especially sheep is exposure to fecal contamination of grazing land (Pathak, 2011). Pathak and Pal (2008) reported that poorly nourished animals maintained on poor quality roughage which are deficient in protein, energy, minerals and vitamins are also susceptible to parasitic infestation. Gastrointestinal parasites have become more difficult to manage in small ruminants because of the parasite increasing resistance to several antihelminthics (Magona et al., 2011). Parasite problems negativity impact the animal's health, reduce productivity and increase treatment costs. The losses caused by parasites can be distinguished into direct and indirect losses (Lüscher et al., 2005). Direct losses include those due to acute illness and death and damage condemnation of organs and cost of dead animal inspection, while indirect losses include the decreases in productive potential such as decreased growth rate, weight loss in young growing animals and late maturity of slaughter stock (Blackburn et al., 2011).

Increasing recognition of the burden of human fascioliasis has occurred and it is now recognized on both public health and transmission through infected fomites or ingestion of infected milk and meat. As an emerging zoonosis by the World Health Organization. The zoonotic disease has a serious impact Livestock get exposed to these pathogenic parasitic organisms very early under natural grazing conditions and the effects of infections are influenced by the environment, nutrition, climate and management ad practices (Blackburn et al., 2011). In keffi abbatoir there is need to know the status of endo parasite infestation in sheep slaughtered, as most of them are not knowledgeable about parasitic infections, this bring about the need to study the endo-parasites infestation of sheep slaughtered in Keffi abattoir, Nasarawa state, Nigeria, for the first time.

\section{Materials and methods \\ Study Area}

This study was conducted in Keffi Local Government Area of Nasarawa State, Nigeria. Keffi is situated on latitude $8^{\circ} 50^{1}, 55^{11} \mathrm{~N}$ and longitude $7^{\circ} 52^{1} 23^{11} \mathrm{E}$. The area falls within the North central region of Nigeria, which is noted for great climatic and seasonal variations. Keffi has an estimated population of 92,664 people (NPC, 2006).

\section{Samples collection and processing}

About $5 \mathrm{~g}$ of fresh fecal samples were collected directly from the rectum of individual sheep through rectal stimulation by fingers using hand gloves between the hours of 7-8am weekly and transferred in to universal clean labeled bottles noting the sex and age (Chees brough, 2005). The samples were taken to the Zoology Laboratory, Faculty of Natural and Applied Sciences, Nasarawa State University, Keffi for parasitological examinations. The identification of the gastrointestinal nematode species was made based on the morphology (Van Wyket al., 2004, Van Wyk and Mayhew 2013).

\section{Parasitological examinations}

Fecal samples were examined by flotation techniques for the presence of gastrointestinal parasites ((Oyerinde, 1999; Cheesbrough, 2005). About 2-3g of the fecal samples were taken in to a mortar, grounded and 
mixed thoroughly in a saturated sodium chloride solution and filtered through a sieve with minute holes into a beaker to remove the large particles. The solution obtained was poured into a small bottle until it was completely filled to make a convex meniscus at the top and covered with a clean grease-free cover slide. After 10 minutes, the cover slide was removed and mounted on a clean slide and examined under the microscope using objective of $10 \times 20$ magnification to determine the presence of eggs (ova).

\section{Sedimentation Method}

About 2-3g of the fecal matter was mixed with water and put in tubes. The tubes were centrifuged for three times for about 5 minutes and each supernatant fluid was removed and replaced each time. The deposits were taken and placed on slides with covers slip and examined microscope at high power $10 \times 40$ magnification for detection of morphological structure of the ova of the helminthes seen.

\section{Statistical analysis}

The data generated were subjected to descriptive statistical analysis using percentages and charts (SPSS version 20.0) and Chi - square analysis was used in determining the prevalence rates in the gender, age and the different types of small ruminants studied. $p<0.05$ was considered indicative of a statistically significant difference.

\section{Results}

A total of 150 slaughtered sheep were examined for gastrointestinal parasites on the basis of age groups as young (1-10 months) and adult (above10 months), sexes (male and female), sheep breed as well as infection among the sheep. The result indicated that only 84 $(56.0 \%)$ were infected (Table 1$)$.

Table 1: Prevalence of intestinal parasite in relation to age and infection percentage.

\begin{tabular}{ccccccc}
\hline Sheep breed & Number & Adult & Young & $\begin{array}{c}\text { No. } \\
\text { examined }\end{array}$ & $\begin{array}{c}\text { No. } \\
\text { infected }\end{array}$ & \%Prevalence \\
\hline Yankasa & 32 & $12(37.5 \%)$ & $19(36.5 \%)$ & 60 & 32 & 38.1 \\
\hline WAD & 12 & $4(12.5 \%)$ & $8(15.4 \%)$ & 18 & 12 & 14.3 \\
Balami & 18 & $7(21.9 \%)$ & $11(21.2 \%)$ & 33 & 18 & 21.4 \\
Uda & 22 & $9(28.1 \%)$ & $14(26.9 \%)$ & 39 & 22 & 26.2 \\
Total & 84 & $32(38.1 \%)$ & $52(61.9 \%)$ & 150 & 84 & 56.0 \\
\hline
\end{tabular}

No significant difference. $(\mathrm{P}$ value $=0.278>0.05)$

Table1: the result showed that Yankasa has the highest percentage prevalence (38.1) while Wad had the list with (14.3\%). No statistical difference in age variation. The overall prevalence of infection based on age groups (young and adult) higher infection rate were observed in young ones than in adult. No significance difference was observed among the age groups, (young and adult as $(\mathrm{P}$ value $=0.174>0.005)$

Table 2: Prevalence of intestinal parasite in relation to sheep breed and sex

\begin{tabular}{lllllll}
\hline Parasites & Yankasa & WAD & Balami & Uda & Female & Male \\
\hline Strongyloites spp & $5(15.6 \%)$ & $2(16.7 \%)$ & $3(16.7 \%)$ & $3(13.6 \%)$ & $8(14.8 \%)$ & $5(16.7 \%)$ \\
Coccidian spp & $2(6.3 \%)$ & $0(0.0 \%)$ & $1(5.6 \%)$ & $1(4.5 \%)$ & $3(5.6 \%)$ & $1(3.3 \%)$ \\
Trichostrongylus spp & $9(28.1 \%)$ & $3(25.0 \%)$ & $5(27.7 \%)$ & $6(27.3)$ & $14(25.9 \%$ & $9(30.0 \%)$ \\
F. gigantica & $2(6.3 \%)$ & $1(8.3 \%)$ & $1(5.6 \%)$ & $1(4.5 \%)$ & $3(5.6 \%)$ & $2(6.6 \%)$ \\
Haemonchus spp & $5(15.6 \%)$ & $3(25.0 \%)$ & $3(16.7 \%)$ & $4(18.2 \%)$ & $10(18.5 \%$ & $5(16.7 \%)$ \\
Oesophagostomus spp & $5(15.6 \%)$ & $2(16.7 \%)$ & $3(16.7 \%)$ & $4(18.2 \%)$ & $10(18.5 \%$ & $4(13.3 \%)$ \\
F. hepatica & $4(12.5 \%)$ & $1(8.3 \%)$ & $2(11.1 \%)$ & $3(13.6 \%)$ & $6(11.1 \%)$ & $4(13.3 \%)$ \\
Total & $32(38.1 \%)$ & $12(14.3 \%)$ & $18(21.4 \%)$ & $22(26.2 \%)$ & $54(64.3 \%$ & $30(35.7 \%$ \\
\hline
\end{tabular}

Table 2: Showed the prevalence of intestinal parasites of sheep among the breeds and sexes with no significant differences in infection rate in both breed and sexes of the sheep ( $(\mathrm{P}$ value $=0.828>0.005$ and $P$ value $=9.689>0.005$ ) respectively . 


\section{Discussion}

The result of the parasitological examination of 150 faecal samples among the sheep studied showed that $84(56.0 \%)$ were infected with different species of gastrointestinal parasites such as Stongyloies spp, Coccidia spp, Fasciola spp, Haemonchus spp and Oesophaghostomus spp. The prevalenced of the gastrointestinal parasites was high in Yankasa breed (38.1\%) than WAD (14.3\%), Uda (26.2\%), and Balami (21.4\%). This might be probably due to the fact that sheep do not normally developed a protective immunity against exposure to an infectious agent (Black burn et al., 2011). The variation in the incidence may be due to different management systems especially those kept under traditional methods of husbandry compounded by additional stress of mal nutrition (Pal and Qayyum, 1993). Infection by these parasites can result in severe effects such as reduced fertility, decreased work capacity, reduction of feed intake and lower weight gain, treatment costs and mortality in heavily parasitized animals (Waller, 2006).

The Various species of endo-parasites encountered in the present study have also been reported previously by (Ayaz et al., 2013), who observed that the higher prevalence of Trichostrongylus spp and Haemonchus spp in Yankasa breed may be attributed to a variety of factors like grazing habit and relatively less environmental cleanliness compared to other (Javed et al., 1992). The prevalence rate of the Trichostrongylus spp reported in this study is in agreement with the result of Fitscher et al.(1993), who observed that Strongyles and Coccidian species are the most common parasites of sheep. In respect to sex specific rate of infection, females showed higher infection rates than males under similar management system. This finding supports the general understanding of helminth infections that female animals are more susceptible to helminthosis (Valcarel and Garcia, 1999). It was also observed that sex is a determinant factor influencing prevalence of parasitism (Adedokum et al., 2008) and females are more prone to parasitism during pregnancy and per parturient period due to stress and decreased immune status (Urguhart et al., 1996).

The results of this study also showed that higher prevalence rate of gastrointestinal parasites was found in young sheep than in the adults. This is similar to the finding of Yohanna et al. (2012) and Bashir et al. (2012). Although all the two age groups were infected but was higher in young animals screened which is in line with the findings of higher prevalence in young animals in Ethiopia (Tefera et al., 2011) and elsewhere (Ibrahim et al., 2008), this might be due to the fact, that younger sheep lack strong immunity compared to the adults. Therefore, infection by gastrointestinal parasites in ruminants including sheep can result in severe economic losses in a variety of ways. They cause loses through infertility, reduced work capacity, a reduction in food intake and lower weight gains, treatment costs, and mortality in heavily parasitized animals (Waller, 2006).

\section{Conclusion}

The result of this finding will be of great assistance in understanding the epidemiology of the endo parasites infection in keffi abattoir. The findings of this study revealed that gastrointestinal parasites encountered in sheep breeds was 56.0\%.The dominant parasites encountered were Ttrongyloides spp, Coccidian spp, Trichostrongylus spp, Haemanchus spp, Fasciola spp, and Oesophagustomus spp. These parasites affected all the animals regardless of ages and sexes in the area.

\section{Acknowledgments}

The author would like to thank the Management of Keffi abattoir for their permission to collect fecal samples from the slaughtered sheep and Mr. Sunday Dickson of Nasarawa State University, Keffi for Technical assistance.

\section{References}

Adedokun, O.A. Ayinmode AB, Fagbemi BO.(2008). A comparative study of three methods for detecting fasciola infections in Nigerian cattle.Vet. Arhiv 78(5): 411-6.

Ayaz, M.M., Raza, M.A, Murtaza, S, Akhtar, S. (2013). Epidemiological survey of helminths of goats in southern Punjab, Pakistan.Trop. Biomed. 30 (1), 62-71.

Badran, I, Abuamsha, R, Aref, R, Alqisi, W. and Alumor, J. (2012). Prevalence and diversity of gastrointestinal parasites in 
small ruminants under two different rearing systems in Jenin district of Palestine. An-Najah University Journal of Research. 26:1-18.

Bashir, A. L. Chishti, M. Z. and Fayaz, A. and Hidayatullah, T. (2012). Helminthic infestations in slaughtered sheep and goatsofdistrictGanderbal, Kashmir.Dav International Journal of Science. 1(1): 65-67.

Besier, R. B. and Love, S. C. (2003). Anthelmintic resistance in sheep nematodes in Australia: the need for new approaches. Australian Journal of Experimental Agriculture.43: 1383-1391.

Blackburn, H. D, Paiva, S. R, Wildeus, S, Getz, W, Waldron, D., Stobart, R., Bixby, D., Purdy, P. H, Welsh, C, Spiller, S, \& Brown, M. (2011). Genetic structure and diversity among U. S. sheep breeds: Identification of the major gene pools. Journal of Animal Science, 89(8), 23362348

Blench, (1999). Coccidia and coccidosis of sheep in the Sudan. PhD. Thesis: University of Khartoum.

Charray, J. M. and Levif, J. (1992).Manual of sheep production in the humid tropics of Africa.CTA CAB International Wilingford Oxon, UK.pp.113.

Cheesbrough, M. (2005).District Laboratory Practice for Tropical Countries.Part 2. Cambridge University Press, UK, 434.

Fritsche, T, Kaufmann, J. and Pfister, K. (1993).Parasite spectrum and seasonal epidemiology of gastro-intestinal nematodes of small ruminants in The Gambia. Veterinary Parasitology, 49: 271-283.

Hassan, D.I., Mbap, S. T., and Naibi, S. A. (2013a).Prevalence of worm infection in Yankasa sheep and West African dwarf goats in Lafia Town and Environs, Nigeria. IOSR Journal of Agriculture and Veterinary Science, 4(4), 84-90.

Hassan, D.I., Musa-Azara, I. S., Mohammed, J., and Zanwa, I. A. (2013b). Influence of age, sex and season on haematology and serum chemistry of Red Sokoto goats in Lafia, Nasarawa State Nigeria. International Journal of Agricultural Science and Veterinary Medicine, 1(4),
57-63

Ibrahim, M. M., Al Ghamdi, M. A., and Alghamdi, M.S. (2008): Helminth community of veterinary importance of livestock in relation to some ecological factors. Turk.Parasitol.Degisi.32(1): 42-47.

Javed, M. S., Iqbal, Z., and Hayat, B. (1992). Prevalence and economics of haemonchosis in sheep and goats.Pakistan Veterinary Journal, 12: 36-38

Lüscher, A. Häring, D. A., Heckendorn, F, Scharenberg, A, Dohme, F, Maurer, V. and Hertzberg, H. (2005).Use of tanniferous plants against gastrointestinal nematodes in ruminants. In: Researching Sustainable Systems International Scientific Conference on Organic Agriculture, Adelaide, Australia, 21-23.

Magona, J., Musisi, G. (2011). Influence of age, grazing system, season and agroclimatic zone on the prevalence and intensity of gastrointestinal strongylosis in Ugandan goats. Small Rumin. Res. 44 (3), 187-192.

Nwosu, C. O., Madu, P.P., and Richards W. S. (2007). Prevalence and seasonal changes in the population of gastrointestinal nematodes of small ruminants in the semi-arid zone of North-Eastern Nigeria. Veterinary Parasitology. 144:118-124.

Olufunmilayo, A., Williams, J. L, Sara, B., and Bardara, U. (2000). Genetic Relationships between Native Sheep breeds in Nigeria based on Microsatellite DNA polymorphisms. Nigeria journal of Animal production 27 (1): $1-8$.

Pathak, A. K. (2011). Nutritional status and performance of ruminants as influenced by gastrointestinal nematodes: An overview. N.E. Vet. 13(3):20-26

Pathak, A. K., and Pal, S. (2008). Seasonal prevalence of gastrointestinal parasites in goats from Durg district of Chhattisgarh. Vet. World. 5: 136-137.

Population Commission's Figures for Nigeria States for 2006 Population and Housing Census-National Population Commission. www.population.gov.ng 
80 | Prevalence of Gastro- intestinal Parasites of Sheep slaugtered at Keffi Abattoir, ...

Tefera, M, Batu G. and Bitew, M. (2011). Prevalence of gastrointestinal parasites of sheep and goats in and around Bedelle, South-Western Ethiopia. International Journal of Veterinary Medicine, 8 (2).

Urquhart, G. M., Armour, J., Duncan, J. L., Dunn, A. M. and Jennings, F. W. (1996)Veterinary Parasitology, 87: 163172.

Van Wyk, J. A, Cabaret, J. and. Michael, L. M. (2004). Morphological identifcation of nematode larvae of small ruminants and cattle simplified, Veterinary Parasitology, vol. 119, no. 4, 277-306
Wyk, J. A., and Mayhew, E. (2013). Morphological identifcation of parasitic nematode infective larvae of small ruminants and cattle: A practical lab guide," Onderstepoort Journal of Veterinary Research, vol. 80, no.1

Waller, P.J, (2006). From discovery to development: current industry perspectives for the development of novel methods of helminth control in sheep and goat.

Yohanna, C.A., Adenkola, A.Y., Kigbu R. (2012). Diseases of sheep and goats in Nasarawa state, Nigeria. Trop Vet. 26(3\&4):31-5. 